$\mathbb{P}$ periodica polytechnica

Mechanical Engineering

$53 / 2(2009) 69473$

doi: 10.3311/pp.me.2009-2.03

web: http://www.pp.bme.hu/me

(c) Periodica Polytechnica 2009

RESEARCH ARTICLE

\title{
Experimental and numerical evaluation of lubricated friction of EPDM rubber
}

\author{
Nándor Békési / Károly Váradi
}

Received 2010-01-18

\begin{abstract}
Lubricated friction between an EPDM rubber plate and a hemispherical steel counter surface was studied both with experimental and numerical methods. The dependence of the coefficient of friction on the normal load and the sliding velocity were investigated by a series of tests, under lubricated friction condition. The experimental setup was then modeled with finite elements, and calculations were done assuming different sliding velocities. The numerical simulation was able to model the dependence of the penetration depth of the counter surface and the size of contact area on the sliding velocity. The calculated coefficient of friction vs. sliding velocity curve shows a good agreement with the measured results.
\end{abstract}

\section{Keywords}

rubber $\cdot$ lubricated friction · modeling

\section{Acknowledgement}

The authors wish to acknowledge the help of Prof. M. Kozma in understanding the characteristics of lubrication. The authors are thankful to Dr. D. Felhôs, Mr. L. Pálfi and the co-workers of the IVW GmbH (Kaiserslautern, Germany) for their help in the experimental tests. This work was performed in the framework of an integrated project of the EU (KRISTAL; Contract Nr.: NMP3-CT-2005-515837; www.kristal-project.org).

\section{Nándor Békési}

Department of Machine and Product Design, BME, H-1111 Budapest, Múegyetem rkp 3., Hungary

e-mail: bekesi.nandor@gt3.bme.hu

\section{Károly Várad}

Department of Machine and Product Design, BME, H-1111 Budapest, Múegyetem rkp 3., Hungary

\section{Introduction}

Rubber parts are frequently used in applications with lubricated friction conditions. Typical lubricated applications of rubber parts are the sealing of rotary shafts or hydraulic cylinders. Windscreen wipers and vehicle tires in wet environment are also examples of lubricated friction of elastomer parts.

In case of lubricated sliding, the coefficient of friction is usually described as a function of load, sliding velocity and temperature (viscosity of lubricant). This kind of behavior was found by Thurston [1], Martens [2] and Stribeck [3] - whom the well known curve is named after - studying lubricated bearings. At lower velocities, no continuous oil film is developed between the two contacting surfaces; and at higher velocities, the greater friction resistance is caused by the speed and temperature dependent viscosity of the lubricant. However, in case of elastomer rubbing parts, the friction has another important component, which also depends on the load, the sliding speed and the temperature. The deformation of the rubber parts in contact is usually significant and accordingly it affects the nature of the frictional contact [4]. When rubber is deformed, due to its visco-elastic properties some of the work invested is dissipated, converted into heat as a consequence of hysteresis. Hysteresis may exert a considerable impact in the case of repeated stresses; at lubricated elastomers as much as $50 \%$ of friction can be attributed to hysteresis [5]. Therefore, in addition to the special mechanical properties of elastomers (high elasticity; non-linear, time and temperature dependent behavior), their friction, wear, and lubrication mechanisms also differ enormously from the processes characterizing the behavior of metals, ceramics, and rigid polymers, therefore their modeling also requires other techniques.

Zhang in [6] summarizes the lubrication theories for rubber seals. The visco-elastohydradynamic (VEHD) lubrication takes into account the visco-elastic and inertial effects of seal materials on the thickness of the lubricating film. The microelastohydrodynamic (MEHD) lubrication theory assumes that the load-carrying capacity of lubricated rough surfaces is the sum of three components, namely the hydrodynamical, the micro-contacting and the squeezing component. The macroelastohydrodynamic lubrication theory of elastomers by Moore 
[7] considers the asperities of the rough counter surface.

Present paper shows experimental and numerical methods for investigating the lubricated friction between EPDM rubber and steel counter part. The effect of the surface roughness on the friction was neglected in the numerical models, since in the given arrangement it was insignificant compared to the friction due to macroscopic hysteresis and the shearing of the lubricant.

\section{Experimental}

The lubricated friction characteristics of EPDM rubber filled with carbonblack were examined in Pin-on-Plate $(\mathrm{PoP})$ arrangement using a Wazau Tribometer Type TRM 1000 (Dr.-Ing. Georg Wazau Mess- und Pruefsysteme $\mathrm{GmbH}$, Berlin, Germany). The specimens were cut out from a $4 \mathrm{~mm}$ thick EPDM plate. The counter surface pressed to the EPDM specimen was a steel pin ending in a hemisphere with a radius of $5 \mathrm{~mm}$. The average roughness $\left(\mathrm{R}_{a}\right)$ of the steel counterpart was less than 0.1 $\mu \mathrm{m}$. Hydraulic fluid Hydraulan 407-1 of BASF (Ludwigshafen, Germany) was used as a lubricant. Due to the horizontal arrangement of the measurement configuration, the entire measurement place was not required to be inundated: lubricant layer of some milliliters thick were sufficient to ensure fluid film lubrication (except in some extreme cases being presented later), because the lubricant remained on the horizontal surface of the EPDM specimen forming an annulus along the circular wear track of the counter surface (Fig. 1).

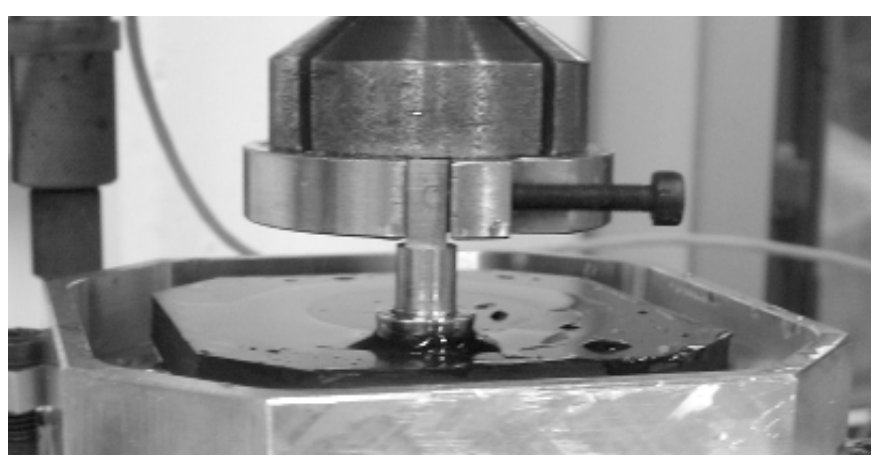

Fig. 1. Lubricated PoP measurement with a spherical pin radius of $5 \mathrm{~mm}$ and an EPDM plate with a lubricant annulus along the wear track

During the series of measurements, the sliding velocity was varied in a wide range (between $3 \mathrm{~mm} / \mathrm{s}$ and $1036 \mathrm{~mm} / \mathrm{s}$ ) together with the load (from $5 \mathrm{~N}$ to $100 \mathrm{~N}$ ). The resulting coefficient of friction was recorded. First, the lowest load was set, to be followed by the lowest sliding velocity. After one minute, the value of the coefficient of friction was read, and then the equipment was set to the next value of sliding velocity. This went on like this until the highest sliding velocity was reached. Then the measuring equipment was shut down and the load was changed to the next value in the sequence (the device did not need to be shut down to change the velocity, but load could only be modified after the device was shut down), and the measurement was repeated again from the lowest sliding velocity, followed by gradual velocity increasing.
As already mentioned, the supply of the contacting area with the fluid lubricant was ensured in nearly all cases. However, at the highest load, sometimes it occurred that the hemisphere pressed to the specimen with so large force that it squeezed the lubricant out of the area between the contacting surfaces. When lower sliding velocities were set, the hemisphere end of the pin separated the lubricant sump, which reunited again behind the pin, while the oil was flowing from the two sides to the middle of the wear path. At higher velocities, however, the lubricant did not have time to flow back after the counter surface passed, and the lubricant was arranged into two concentric rings on the two sides of the track on the EPDM plate. Between the two oil rings, lubricant only remained in the form of tiny drops hardly visible to the naked eye (diameters of drops were some tenths of millimeters).

In order to examine wear of EPDM in a fully lubricated state, a very lengthy measurement was carried on. This measurement was conducted at a sliding velocity of $250 \mathrm{~mm} / \mathrm{s}$ and a load of 5 $\mathrm{N}$. The duration of measurement was 15 hours. Fluid lubrication was ensured throughout the entire measurement. Upon examining the specimen surface after the measurement, no detectable wear could be observed after 15 hours of running. Nevertheless determining the amount of wear is a challenging task, especially in case of lubricated friction. The methods applied in the course of wear measurements in dry friction (like in [8]) - essentially specimen weighing before and after the tests - cannot be implemented here. On the one hand, in the lubricated case, the scale used for measuring such minimum actual weight loss by wear is not suitable for the purpose - however relatively accurate (the weight loss by wear measured in a dry state was usually some milligrams). On the other hand, some part of the lubricant is absorbed on the elastomer specimen during the experiment (due to the phenomenon of swelling), therefore the weight is changed.

The other method coming in handy is to measure volume loss by wear. This essentially means that some sort of surface inspecting device is used for examining the worn specimen and conclusions are drawn as regards volume loss by wear on the basis of the dimensions and shape of wear tracks [9]. However, during lubricated measurements, the elastomer material shows considerable creeping due to contact pressure resulting from relatively high loads and long sliding time compared to dry measurements. After measurements, a depression could be observed even with the naked eye on the specimen surface at the place corresponding to the expected wear track, but the surface texture did not change (Fig. 2).

\subsection{Results of the experimental tests}

The measured coefficient of friction as a function of sliding velocity and normal force is shown in Fig. 3

On the basis of the results of the lubricated tests it can be established that the coefficient of friction of the system increases as the load is increased; it decreases by increasing the velocity, and, in some cases, it rises again at higher velocities. However, 


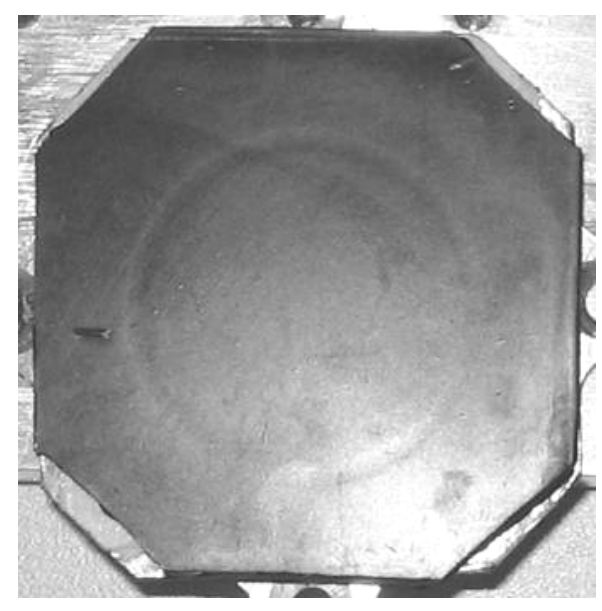

Fig. 2. Specimen surface after 15 hours of lubricated sliding. Appearance of the ring-shaped groove is due to creeping rather than wear since the surface quality has not changed. (Diameter of the track is $33 \mathrm{~mm}$.)

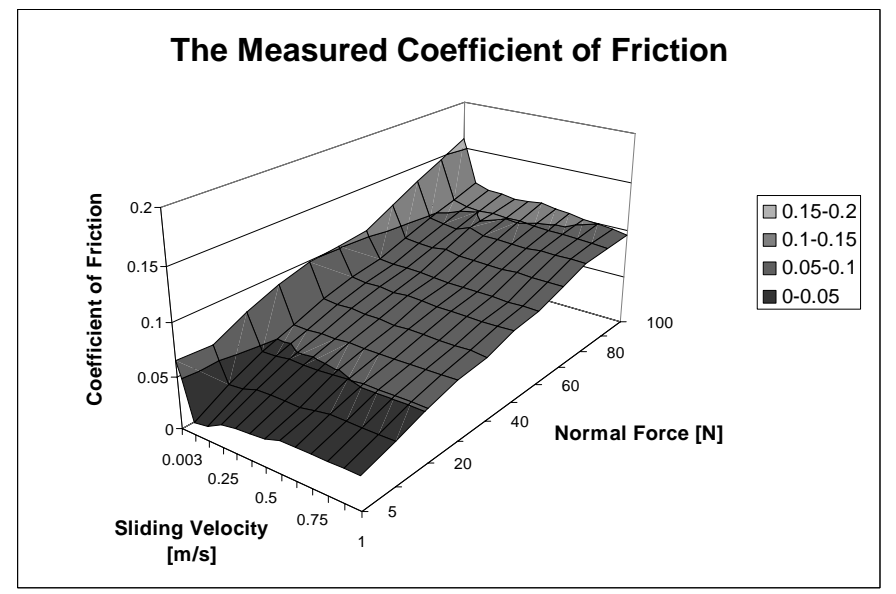

Fig. 3. The measured coefficient of friction as a function of the normal force and sliding velocity in PoP arrangement, spherical counter surface (SR5)

the dependence of the coefficient of friction on the sliding velocity can be explained by the Stribeck curve only in cases of lower normal forces.

In order to explain dependence of the coefficient of friction on the normal force, the time-dependent visco-elastic behavior of the elastomer material must be taken into consideration. Some part of the friction resistance of elastomer materials is due to hysteresis, the internal friction of the material. In the arrangement examined, the specimen was deformed to a larger extent by the spherical surface of the pin as a result of the higher normal force, involving an increase in the so-called excited volume where hysteresis loss is produced.

As a result of a higher load, the counter surface was pressed deeper into the specimen's surface, enlarging the contact area also. Therefore the friction resistance attributable to boundary layer friction - predominant at lower sliding velocities - increases, and the friction due to fluid film shearing also increases, which is characteristic at higher sliding velocities. Thus the coefficient of friction increases at all examined sliding velocities as the normal force increases.

In order to explain the velocity dependence of the coefficient of friction, the visco-elastic property of the elastomer material must also be taken into consideration. At lower loads, the excited volume will be smaller, coupled with relatively small depression, thus velocity dependent hysteresis exerts a smaller impact on friction resistance. When higher loads are set, however, a larger excited volume causes a greater prevalence of viscoelastic impacts. In these cases, if sliding velocity is increased during the measurement, the elastomer material of the specimen behaves like it was harder, and because of this, the penetration depth of the steel counter surface is reduced. This could be observed even with the unaided eye during measurements: at the highest loads (80 and $100 \mathrm{~N}$ ), there were several tenths of millimeters of differences between the penetration depth values observed at the lowest and the highest velocities. This can also explain the fact that while the measured coefficient of friction increases by increasing the velocity at lower and medium loads $(5-50 \mathrm{~N})$ and in the higher velocity range $(0.6-1 \mathrm{~m} / \mathrm{s})$, at higher loads $(100 \mathrm{~N})$ the coefficient of friction decreases in this velocity range. A decreased penetration depth due to higher sliding velocity results in a decreased contact area as well as a reduction in the excited volume. For these reasons, friction resulting from fluid film shearing is expected to decrease on one hand because of the reduced contact area and on the other hand to increase due to the increased shearing rate of the lubricant film. Internal friction coming from hysteresis is decreased as the excited volume is reduced. These are in accordance with other studies (e.g. in [10], [11]). The exact contribution of the volumetric (hysteretic) and the surface friction is unknown, hence the measured total coefficient of friction decreases in this case.

\section{Modeling lubricated friction}

In order to obtain a detailed insight of the complex friction phenomenon numerical simulations were performed.

A finite element model of the test arrangement described above was produced. In this $3 \mathrm{D}$ model, the specimen was modeled by 1250 three-dimensional, eight-node brick elements [12], but after local remeshing (adaptive element splitting [13]), the model consisted of 7410 elements by the end of the calculation (Fig. 4). The length of the elements' edge varied between 0.5 and $2 \mathrm{~mm}$. The lubricant was not modeled in the calculations, the effect of lubricated friction was considered as a constant prescribed coefficient of friction between the rubber and the counterpart, as described later.

\subsection{Material properties}

The non-linear material behavior of the elastomer specimen was taken into consideration by using a two-parameter MooneyRivlin model $\left(\mathrm{C}_{10}=320 \mathrm{MPa}, \mathrm{C}_{01}=80 \mathrm{MPa}\right)$, and its viscoelastic properties by a 15 -term generalized Maxwell model. The material properties of the rubber were derived based on stress relaxation measurements (the material properties described in reference [14] were used for modeling). The substrate to which the specimen was affixed before the measurement and the hemi- 




Fig. 4. 3D finite element model (the elements are dark; the surfaces considered to be rigid are light grey). Adaptive local remeshing was applied in the contact area.

spherical counter surface were considered to be ideally rigid. This assumption is reasonable if one considers the fact that the steel has four orders of magnitude higher elastic modulus than the rubber specimen.

\subsection{Loads and contact conditions}

The $100 \mathrm{~N}$ load acted on the substrate, and the hemispherical counter surface was moving along the circular track of $33 \mathrm{~mm}$ diameter in accordance with the measurement, at various sliding velocities applied in the measurement as well. No displacement was possible between the substrate and the specimen; the coefficient of friction specified between the specimen and the counter surface was defined at $\mu=0.06$ in order to take into consideration the friction developing on the rubbing surfaces. The value of the surface coefficient of friction was determined by a preliminary $\mathrm{FE}$ calculation at $3 \mathrm{~mm} / \mathrm{s}$. In this preliminary calculation the surface friction was neglected, so there was no coefficient of friction prescribed between the contacting surfaces. The calculated coefficient of friction was then subtracted from the measured one and the result was applied as the surface coefficient of friction.

In the simulations, load was added to the model gradually within the period of $0-0.1 \mathrm{~s}$; the counter surface started to rotate afterwards. In case of each sliding velocity, the sliding time was divided into 1000 increments, during which the counter surface revolved around twice, since due to the local remeshing, the results showed some scattering during the first revolution. The results shown below were taken at the end of the second revolution, when the steady state was achieved.

\subsection{Results of the simulations}

Fig. 5 shows the contact area and the penetration depth of the counter surface for the sliding velocities examined.

Based on the results, it can be established that the counter surface moving at a higher velocity can be pressed into the rubber surface to a lesser extent; thereby the contact area will also be smaller. There is a $0.25 \mathrm{~mm}$ difference between the penetration values corresponding to the lowest and the highest velocity, respectively.

After the calculations, the total friction resistance correspond-

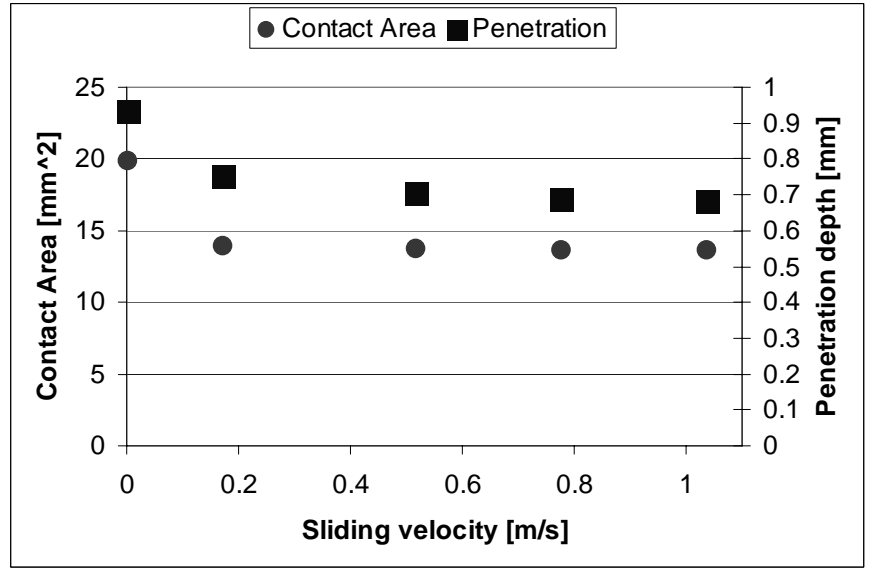

Fig. 5. Contact area and penetration depth of the counter surface in function of sliding velocity

ing to each velocity value was also specified. Friction torque (torque of the counter surface in direction $\mathrm{z}$ ) was queried from the finite element result files, and the coefficient of friction was calculated therefrom. Changes in the coefficient of friction calculated from the reaction torque are shown in Fig. 6. The figure also indicates measured results corresponding to the examined load of $100 \mathrm{~N}$.



Fig. 6. Coefficient of friction in function of sliding velocity

\section{Conclusions}

Fig. 6 shows that the velocity dependence of the coefficient of friction determined in the course of the series of measurements conducted in lubricated friction was successfully modeled by the series of calculations. The measured and calculated values of the coefficient of friction show good agreement. At the highest sliding velocity, lubricant viscosity probably decreased so much due to friction heat generation in the course of the measurement that a greater difference was produced than could be observed at the other velocities, since the surface friction due to mixed lubrication and lubricant film shearing was considered as a constant prescribed coefficient of friction in the calculations. 


\section{References}

1 Thurston R H, Friction and lubrication - Determination of the laws and co-efficients of friction by new methods and with new apparatus, Trübner and Co., Ludgate Hill, London, 1879.

2 Martens A, Schmieröluntersuchungen (Investigations on oils) Part I: Mitteilungen aus den Königlichen technischen Versuchsanstalten zu Berlin, Ergänzungsheft III (1888), 1-37.

3 Stribeck R, Kugellager für beliebige Belastungen Zeitschrift des Vereins Deutscher Ingenieure 45 (1901), no. 3, 73-79.

4 Hammock B J, Lubrication of Machine Elements, NASA Reference Publication, Cleveland, Ohio, USA, 1984.

5 Persson B N J, Volokitin A I, Rubber friction on smooth surfaces, The European Physical Journal E 21, posted on 2006, 69-80, DOI 10.1140/epje/i2006-10045-9, (to appear in print).

6 Zhang S W, Tribology of Elastomers, Tribology and Interface Engineering Series, posted on 2004, no. 47, DOI 10.1016/S0167-8922(04)80006-3, (to appear in print).

7 Moore D F, The friction and lubrication of elastomers, Pergamon Press, Oxford, New York, 1972.

8 Karger-Kocsis J, Mousa A, Major Z, Békési N, Dry friction and sliding wear of EPDM rubbers against steel as a function of carbon black content, Wear 264 (2008), 359-367, DOI 10.1016/j.wear.2007.03.021. Issues 3-4.

9 Karger-Kocsis J, Felhős D, Xu D, Schlarb A K, Unlubricated sliding and rolling wear of thermoplastic dynamic vulcanizates (Santoprene $(\mathbb{R})$ ) against steel, Wear 265 (2008), 292-300, DOI 10.1016/j.wear.2007.10.010. Issues 34.

10 Person B N J, Sliding friction, Surface Science Reports 33 (1999), 83-119.

11 Kaneko D, Oshikawa M, Yamaguchi T, Gong J P, Doi M, Friction Coefficient between Rubber and Solid Substrate - Effect of Rubber Thickness, Journal of the Physical Society of Japan 76 (2007), no. 4, DOI 10.1143/JPSJ.76.043601.

12 2007. MSC.Marc 2007 r1 Element Library. MSC.Software Corporation. Santa Ana, CA, USA.

13 2004. MSC.Marc Mentat Help Reference. MSC.Software Corporation. Santa Ana, CA, USA.

14 Pálfi L, Goda T, Váradi K, Theoretical prediction of hysteretic rubber friction in ball on plate configuration by finite element method, eXPRESS Polymer Letters 3 (2009), no. 11, 713-723, DOI 10.3144/expresspolymlett.2009.89. 